\title{
In memoriam Fernando de Szyszlo en la boca de la sombra, bajo el Arco Iris negro
}

(1925-2017)

Visité muchas veces a Fernando de Szyszlo en su casa de la calle Ugarte y Moscoso. Siempre, en el vasto tallersalón lleno de libros, de esos enigmáticos personajes blancos de la cultura chancay y de numerosos objetos mágicos, había un lienzo - apenas esbozado, medio acabado o casi completamente terminado- que dominaba por sus impresionantes dimensiones y figuras inquietantes el cuadrado de sillones negros donde íbamos a sentarnos. Charlábamos de todo, especialmente de los acontecimientos de la vida que transcurría y de nuestros autores preferidos, de las exposiciones que preparaba, pero jamás de sus cuadros, de su trabajo en curso o de su obra en general. Jamás me mostró algo suyo aparte del cuadro que estaba en proceso de ejecución, jamás, salvo la última vez que lo visité, hace casi dos años. Me llevó a un rincón de la sala, en la penumbra debajo de la escalera fatal donde cayó con su amada esposa Lila para siempre, y me enseñó una obra suya que al parecer tenía una importancia particular para él. Era un panel vertical de buen tamaño, tal vez más de un metro de altura, negro, un grabado, me dijo con su sonrisa modesta. Y, unos largos segundos, me quedé inmóvil, petrificado delante de esta obra absolutamente, profundamente negra, de un negro tan intenso que parecía lleno de un silencio sideral, el negro del universo después de la desaparición de los planetas y estrellas o quizás, más bien al revés, antes del big bang, 
un negro lleno de energía invisible e inalcanzable, un negro venido de otro mundo más allá del mundo.

$\mathrm{Ni}$ comentamos la obra. Me fui con las resonancias profundas que ella había provocado en mí. Iba más allá en la abstracción que las pinturas monócromas de Mark Rothko o Yves Klein, más profundo que Hans Hartung con «sus maravillosos trazos negros» ${ }^{1}$ o Pierre Soulages buscando el noir-lumière o el outrenoir. Tenía la impresión, con esta obra única - una proeza por sus proporciones y su perfección técnica- que Szyszlo había alcanzado lo que buscó toda su vida: hacer EL cuadro, volverse por fin «el pintor de un solo cuadro». Yo no sé si él sintió, a los noventa y un años, que este grabado representaba el fin de su búsqueda, que el negro total —el color que «otorga misterio y magia al cuadro, tal como yo lo concibo» ${ }^{2}$ - había llegado a su culminación, que por fin había escuchado lo que sale de la boca de la sombra de los surrealistas, siguiendo a Victor Hugo, y visto «este negro Arco Iris» del poema quechua sobre la muerte del Inca Atahualpa, pero lo cierto es que la atención especial que manifestó por esta obra delante de mí fue una señal de alerta sobre su significación.

En cierta forma, este grabado simboliza y sintetiza el anhelo y el alcance de toda una vida. Cumplió con su meta de artista, enunciada con magnífica soberbia -y evidente modestia- en el incipit de sus memorias: «Soy pintor» ${ }^{3}$. Si bien su pintura es totalmente personal, habiendo integrado muy tempranamente las

\footnotetext{
F. de Szyszlo. La vida sin dueño. Madrid, Alfaguara, 2017, pág. 161.

2 Id., pág. 148.

3 Id., pág. 13.
} 
influencias de Pettoruti y Tamayo, las correspondencias con Hartung y Soulages y las lecciones del Renacimiento italiano, no se apartó jamás de sus dos fuentes de inspiración permanente: el arte precolombino y la poesía de vanguardia. Doble linaje que se manifiesta por un vocabulario plástico heredado de las culturas chavín, chancay y paracas, reelaborado para integrar una sintaxis y una gramática que pertenecen al arte occidental del siglo XX. Doble filiación que corresponde también a sus padres, uno europeo y científico —el polaco Vitold de Szyszlo, imagen de la modernidad-, y una peruana - María Valdelomar Pinto, que contaba con un hermano poeta ilustre: Abraham Valdelomar-. Pero la obra de Szyszlo no juega con la confrontación de dos universos mentales y artísticos tan heterogéneos, tan lejanos uno del otro. Más bien, Szyszlo se empeñó en realizar una síntesis a través de una lenta, progresiva y obstinada profundización.

Así su obra desconoce los períodos o las rupturas. Su arte siguió una línea muy firme, desarrollándose en series de cuadros durante años como variaciones sobre un tema que su compositor preferido - J. S. Bach-llevó a su cumbre, según un movimiento continuo de florecimiento propio de la naturaleza como de la cultura. Unas se originan en la historia colonial del Perú como La ejecución de Túpac Amaru, otras surgen de la contemplación de los paisajes desiertos de la costa del Pacífico: Camino a Mendieta o El mar de Lurín. Pero la mayoría nació de la afición de Szyszlo por la poesía y se nutrió de los grandes poetas peruanos: César Vallejo (Homenaje a Vallejo), Emilio Adolfo Westphalen (Abolición de la muerte), César Moro, o el poeta quechua anónimo que cantó la muerte 
del Inca Atahualpa (Cajamarca, Sol negro, Apu Inca Atahuallpaman), como también de los extranjeros: Saint-John Perse (Anabase) y Beckett (L'innombrable). No es extraño que de joven se enamorara de una poeta, Blanca Varela, y se casara con ella, en los tiempos donde descubría maravillado los esplendores de la pintura en Italia y Francia y los encantos de los poetas de la modernidad.

Mario Vargas Llosa, su amigo de toda la vida, afirmó que Szyszlo hubiera alcanzado una fama internacional mucho más grande si se hubiera quedado en Europa o trasladado a Estados Unidos. Es posible, pero no es cierto. Szyszlo volvió a Perú en 1955, después de cuatro años en París y uno en Florencia, empujado por la necesidad íntima de desarrollar su obra en su país, a pesar de sus limitaciones como foco de creación artística o -más bien-a razón de las riquezas de su acervo cultural antiguo que él quería hacer suyo. Hacerse pintor en el Perú de los años cincuenta era un reto mucho más desafiante que quedarse como métèque en un París muy acogedor para los artistas del mundo pero donde el medio artístico podía absorberlo y separarlo de sus raíces. Ante todo, era tal vez la única manera de cumplir con su meta de artista:

Mi relación con el arte siempre ha sido del mismo género: nunca he buscado otra cosa que seguir ese hilo de Ariadna que idealmente me conduciría, mejor, me podría conducir, a esa región donde las formas no son sino la delgada y transparente envoltura de significados palpitantes, y en donde el arte entra oscuramente en el mundo de lo que se llamaba lo sagrado ${ }^{4}$.

4 F. de Szyszlo. El lugar, los instrumentos. Bogotá, Arte Dos Gráfico, 1991. 
Para él, lo sagrado se escondía en las piedras de chavín, en las arcillas cocidas de chancay, en las telas de paracas. El camino para acercarse a ellas pasaba por las formas no figurativas pero sugestivas de la mesa, la cama, el altar, lugares consagrados por un ritual: la comida, el amor, el sacrificio. También por el juego de la luz y de la sombra, el claroscuro que realza los colores suntuosos, mágicos, del acrílico y genera una atmósfera de cataclismo inminente, de violencia a punto de estallar.

Sin rebajar un ápice su alta exigencia de artista, Szyszlo no concebía su oficio como una actividad desconectada de la sociedad, encerrada en la torre de marfil. Si su arte fue siempre alejado de los acontecimientos del tiempo vivido, su persona estaba hondamente involucrada en la vida peruana. Siempre estuvo al tanto de los eventos que tocaban al quehacer nacional y quiso tomar la palabra públicamente cuando lo estimaba necesario. Así que sus notas y crónicas en los diarios, especialmente El Comercio, se referían con preferencia a temas artísticos cuando sus entrevistas y cartas al editor tocaban asuntos políticos, sin temor a la polémica, como lo atestigua el volumen de sus Miradas furtivas ${ }^{5}$. Pero no quería involucrarse directamente en la política, expresar cualquier militancia, adherirse a una clase $u$ otra de ideología: afirmaba sin vacilar su posición firme de hombre libre con una vida sin dueño según el título de sus memorias. Por eso, la única excepción que se permitió en toda su vida fue participar en forma muy activa en

5 F. de Szyszlo. Miradas furtivas. México, Fondo de Cultura Económica, 1996. 
el Movimiento Libertad de oposición a la nacionalización de los bancos por el presidente Alan García en 1987 y luego de apoyo a la candidatura de Mario Vargas Llosa a la presidencia de la República en 1990. Fue cuando Szyszlo sintió que se perfilaba por primera vez la oportunidad de modernizar el Perú - llevándolo al círculo de los países avanzados-; es decir, cumplir con sus anhelos de juventud: «No creo que sea inútil precisar aquí que [Luis Miró Quesada y yo] estuvimos juntos en esta empresa no porque eramos amigos de Mario sino porque estuvimos dispuestos a soñar con él este sueño» ${ }^{6}$. Pero aparte de acoger a los amigos fundadores del movimiento en su taller ${ }^{7}$ y dibujar el logotipo de Libertad, se quedó al margen de toda participación en la dirección del efímero partido. El compromiso temporario y algo modesto de Szyszlo con la política no le dio figura partidaria sino que consolidó su autoridad moral, fruto de su apego a la defensa de la libertad en democracia.

No sé si Fernando de Szyszlo tuvo en los últimos tiempos de su vida una mirada para el espejo negro sin reflejo que le tendía su grabado, pero frente a la boca de sombra, quizás pudo sentir la felicidad de haber alcanzado el cuadro perfecto, pintando este imposible Arco Iris negro que señala la muerte y la gloria de una civilización esplendorosa y de un hombre sacralizado. Con su vida recta, su vocación de artista y de humanista

6 Id., pág. 205.

7 «El Movimiento Libertad se fraguó en el estudio de un pintor. [...] De las metas que nos fijamos en aquella conversación de muchas horas bajo el maleficio de los cuadros de Szyszlo, la que logramos a cabalidad fue el programa». Mario Vargas Llosa, El pez en el agua. Barcelona, Seix Barral, 1993, pág. 157. 
cumplida humildemente pero con plena conciencia de su valor, Szyszlo pudo tener la satisfacción de ubicarse espiritualmente a la altura de sus mitos íntimos.

El Perú tiene con Fernando de Szyszlo uno de sus héroes del espíritu.

DANIEL LEFORT 